\title{
Decreased Opioid Consumption and Length of Stay Using an IPACK and Adductor Canal Nerve Block Following Total Knee Arthroplasty
}

Christian Eccles, MD, Andy Swiergosz, MD, Austin Smith, MD, Samrath Bhimani, MD, Langan Smith, BS, and Arthur Malkani, MD

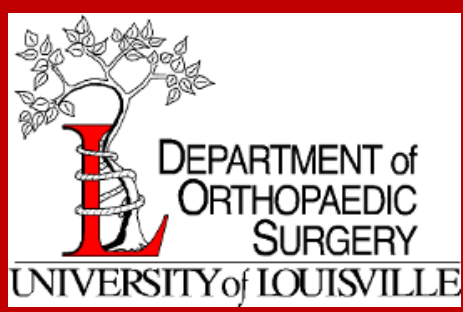

Introduction

Total knee arthroplasty (TKA) is a very successful treatment for end-stage knee osteoarthritis but many patients undergoing this can experience significant postoperative pain.

Peripheral nerve blocks such as a femoral and sciatic block combination have proven to provide effective pain relief following TKA. However, some of these nerve blocks have residual motor deficits which prevent immediate postoperative ambulation and prevent early hospital discharge.

The purpose of this study was to compare outcomes in patients undergoing primary TKA with femoral and sciatic (Fem+Sci) nerve blocks versus the interspace between the popliteal artery and the posterior capsule of the knee and adductor canal (IPACK+ACB) combination sensory nerve blocks.

\section{Methods}

100 consecutive primary TKAs performed by a single surgeon using the same surgical approach and implant design were prospectively reviewed.

The first 50 patients received Fem+Sci nerve blocks and the second 50 received IPACK+ACB blocks preoperatively.

\section{Differences in opioid} requirements, length of stay (LOS), distance walked, Western Ontario McMasters University Osteoarthritis Index (WOMAC), Knee Society (KSS) function scores, Visual Analog Scores (VAS) for pain at rest and with activity, and postoperative complications were analyzed. There were no differences between groups with respect to age, sex, ASA
Images and Tables

Results

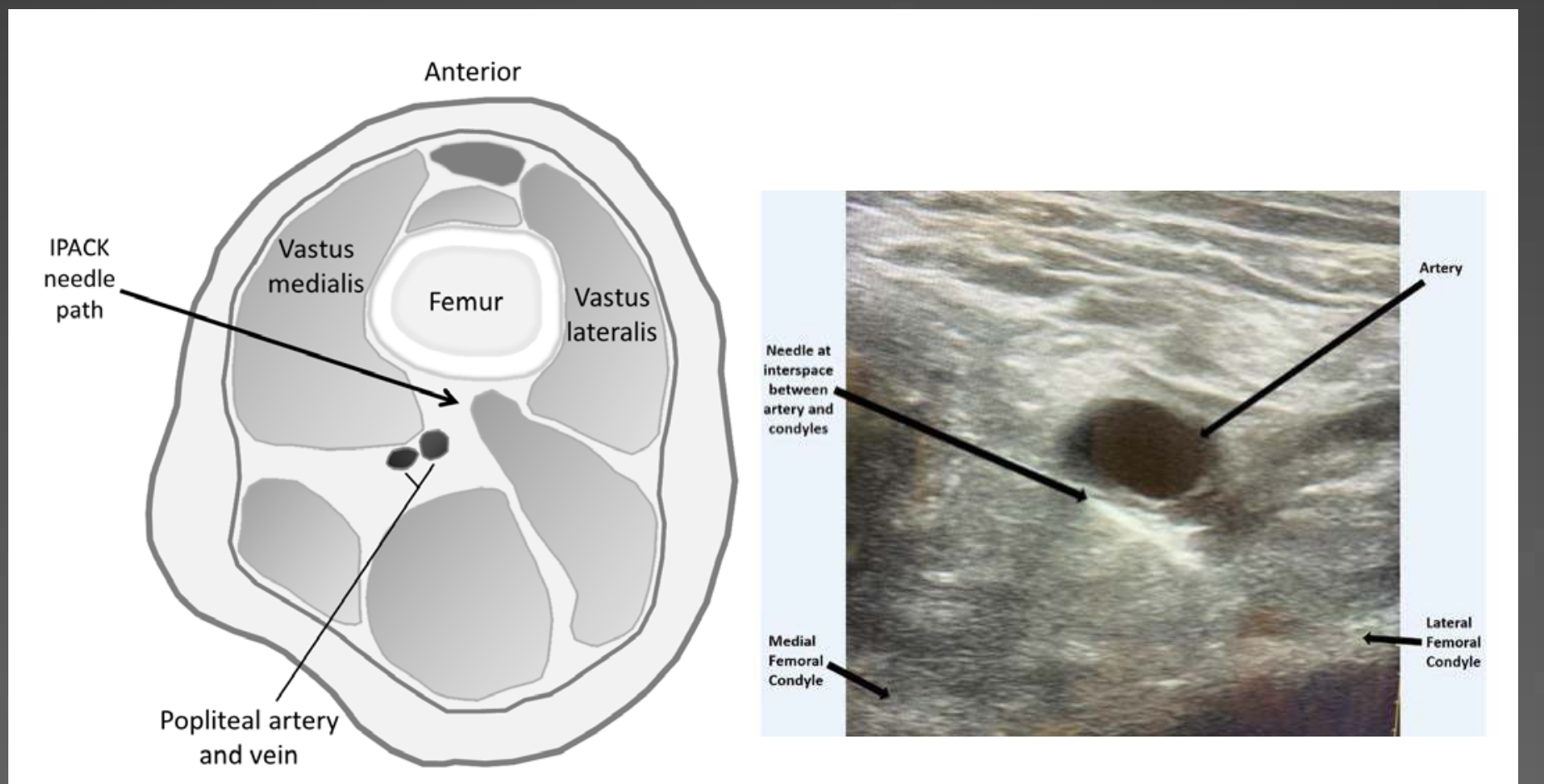

Axial cross sectional image of the distal thigh showing the needle path for the IPACK (interspace between the popliteal artery and posterior capsule of the knee) sensory nerve block

\begin{tabular}{|c|c|c|c|c|}
\hline \multicolumn{5}{|c|}{ Patient Demographics } \\
\hline $\begin{array}{c}\text { Number of } \\
\text { patients }\end{array}$ & 100 & 50 & 50 & $\begin{array}{c}\text { p-value } \\
\text { difference } \\
\text { between groups }\end{array}$ \\
\hline $\begin{array}{c}\text { Preoperative } \\
\text { Diagnosis }\end{array}$ & $\begin{array}{c}\text { Osteoarthritis: } \\
100\end{array}$ & $\begin{array}{c}\text { Osteoarthritis: } \\
50\end{array}$ & $\begin{array}{c}\text { Osteoarthritis: } \\
50\end{array}$ & - \\
\hline Males & $35(35 \%)$ & $16(32 \%)$ & $19(38 \%)$ & $p=0.6753$ \\
\hline Females & $65(65 \%)$ & $34(68 \%)$ & $31(62 \%)$ & $p=0.6753$ \\
\hline $\begin{array}{c}\text { Mean Age at } \\
\text { Surgery (Years) }\end{array}$ & $65.2 \pm 9.2$ & $65.5 \pm 9.7$ & $64.9 \pm 8.7$ & $p=0.7380$ \\
\hline $\begin{array}{c}\text { Mean BMl } \\
\left.\text { (kg/m }{ }^{2}\right)\end{array}$ & $29.5 \pm 4.8$ & $29.9 \pm 4.8$ & $29.1 \pm 4.8$ & $p=0.3955$ \\
\hline $\begin{array}{c}\text { Mean ASA } \\
\text { score }\end{array}$ & 2.37 & 2.31 & 2.44 & $p=0.208$ \\
\hline $\begin{array}{c}\text { Mean Length of } \\
\text { Stay (Days) }\end{array}$ & $1.8 \pm 0.7$ & $1.48 \pm 0.74$ & $2.02 \pm 0.55$ & $p<0.0001$ \\
\hline
\end{tabular}

\begin{tabular}{|c|c|c|c|}
\hline \multicolumn{4}{|c|}{ Discharge Date } \\
\hline \multirow{4}{*}{ IPACK+ACB } & POD\#1 & 31 & $62 \%$ \\
\cline { 2 - 4 } & POD\#2 & 16 & $32 \%$ \\
\cline { 2 - 4 } & POD\#3 & 1 & $2 \%$ \\
\hline \multirow{4}{*}{ FEM+SCI } & POD\#1 & 7 & $14 \%$ \\
\cline { 2 - 4 } & POD\#2 & 35 & $70 \%$ \\
\cline { 2 - 4 } & POD\#3 & 8 & $16 \%$ \\
\hline \multirow{4}{*}{$p$-value } & POD\#1 & $p<0.0001$ \\
\cline { 2 - 4 } & POD\#2 & $p=0.0003$ \\
\cline { 2 - 4 } & POD\#3 & $p=0.0309$ \\
\hline
\end{tabular}

\begin{tabular}{|c|c|c|}
\hline \multicolumn{3}{|c|}{ Physical Therapy } \\
Performance \\
\hline & $\begin{array}{c}\text { Distance } \\
\text { walked POD\#0 } \\
(\mathrm{ft})\end{array}$ & $\begin{array}{c}\text { Distance } \\
\text { walked POD\#1 } \\
(\mathrm{ft})\end{array}$ \\
\hline IPACK+ACB & 21.40 & 204.40 \\
\hline FEM+SCI & 5.31 & 155.17 \\
\hline p-value & $<0.0001$ & 0.0111 \\
\hline
\end{tabular}

Ultrasound of the distal thigh showing the needle path for the IPACK sensory nerve block

$62 \%$ of patients were discharged on postoperative day (POD) \#1 in the IPACK+ACB group compared to $14 \%$ in the Fem+Sci group $(p<0.0001)$.

The IPACK+ACB patients had a shorter LOS (average 1.48 days verses 2.02 days, $p<0.0001$ ), ambulated further on POD\#0 (average 21.4 feet verses 5.3 feet, $p<0.0001$ ), required less narcotics the day after surgery (average 15.7 verse 24.0 morphine equivalents $p<0.0001$ ) and at 2 weeks postoperative (average 6.2 verse 9.3 morphine equivalents, $p=0.025$ ), and required less manipulations for postoperative stiffness (1 verses $5, p=0.204$ ).

WOMAC, KSS, and VAS scores were not significantly different between groups.

\section{Conclusion}

Given the expected future increase in patients undergoing primary TKA along with the subsequent increased healthcare system cost burden and current emphasis on reducing opioid consumption due to concerns of abuse and addiction, decreasing length of stay and opioid consumption are of paramount interest to all stakeholders.

This study suggests that the use of a combination IPACK and adductor canal block will provide improved ambulation leading to earlier discharge and decrease postoperative opioid consumption and appears to be a better alternative to femoral and sciatic motor nerve blocks for primary TKA patients. 